Article

\title{
Experimental Investigation on Combustion Characteristics of Hybrid Rocket Fuels with Multi-Angle Diverging Injector
}

\author{
Pragya Berwal ${ }^{1, *(\mathbb{D} \text { and Shelly Biswas }}{ }^{2}$ \\ 1 Department of Aerospace Engineering, Indian Institute of Technology, Bombay, Powai 400076, India \\ 2 Department of Space Engineering and Rocketry, Birla Institute of Technology, Mesra, Ranchi 835215, India; \\ shellybiswas@bitmesra.sc.in \\ * Correspondence: 184010007@iitb.ac.in
}

Received: 7 April 2020; Accepted: 8 June 2020; Published: 10 June 2020

check for updates

\begin{abstract}
Injection pattern of the oxidizer injected into the combustion chamber is a significant factor in evaluating the performance of a hybrid rocket. In the hybrid rocket combustion process, oxidizer flows over the solid fuel grain surface, leading to a turbulent diffusion boundary layer formation and the flame is established inside the boundary layer. The heat transfer from flame to the fuel surface leads to pyrolysis of the fuel. The heat fluxes, due to pyrolysis, block the heat transfer further to the fuel surface, thus reducing the fuel regression rate. An attempt has been made in this paper to design and study the effect of the multi-angle diverging injector on the enhancement of the fuel regression rate and combustion efficiency of the hybrid rocket. The designed injector was compared with a shower head injector i.e., axial injector. The fuels used were paraffin wax and polyvinyl chloride $(\mathrm{PVC})$ with gaseous oxygen as oxidizer. The effect of formation of the re-circulation zone and flow velocity were studied numerically by a cold flow simulation using ANSYS-Fluent software. It has been observed that direct impingement of the multi-angle diverging injector produces velocity in three directions, leading to distortion of the boundary layer. An increase of $8 \%$ in the average fuel regression rate for PVC fuel grain and $36.14 \%$ for paraffin wax fuel grain was observed, as compared to the shower head injector for the same oxidizer mass flow rate. A combustion efficiency increase of $38 \%$ and $14 \%$ was also observed using multi-angle diverging injector for PVC and paraffin wax fuel grains, respectively. A reduction in sliver and uniform fuel consumption was also observed using the novel multi-angle diverging injector.
\end{abstract}

Keywords: hybrid rocket; injection pattern; regression rate; paraffin wax; polyvinyl chloride

\section{Introduction}

Hybrid rocket engines are those engines which use oxidizer and fuel of different physical states i.e., liquid or gaseous oxidizer and a solid fuel. Generally, fuel is present in the combustion chamber in solid phase and the liquid or gaseous oxidizer is injected into the combustion chamber through an injector. The two propellants are ignited with the help of an external heat source. The solid fuel grain surface undergoes pyrolysis (as in case of polymeric fuels) or melting (as in case of paraffin wax) and, hence, it leads to chemical changes like de-polymerization and vaporisation, respectively. This vaporized fuel further mixes with the oxidizer to undergo combustion, which further expands the combustion products through the nozzle to develop thrust [1]. The hybrid rockets provide several advantages over the solid and liquid propellant rockets, such as simplicity, safety, lower cost and thrust tailoring. The fuel regression rate is the key parameter for the characterization of the hybrid rocket's performance [2]. 
It was widely demonstrated, both theoretically and experimentally, that the regression rate of the solid fuel grain depends upon the convective heat transfer from the flame to the fuel surface, where negligible radiation was considered. Marxman and Gilbert [3] proposed a turbulent boundary layer regression rate model yielding that the rate of fuel consumption is fundamentally governed by mass flux $\left(r \propto G^{0.8}\right)$. Generally, at lower or higher mass fluxes, another influencing factor on the regression rate for certain solid fuels was found to be pressure. Several investigators credited this effect to either wall heterogeneous reactions with the oxidizer [4], or finite rate gas phase chemical kinetics [5].

In spite of its various advantages, hybrid rocket engines face some difficulties [6] which need to be overcome to enhance its level of performance, such as low regression rate, reduced combustion efficiency, combustion instability and shift in $\mathrm{O} / \mathrm{F}$ (oxidizer-to-fuel ratio). There have been several techniques proposed to enhance the regression rate of solid fuel in hybrid rockets, such as use of protrusion [7], use of multi-port grain [8], use of cryogenic fuels [9], high mixture ratio, swirl flow of oxidizer inside the chamber, particle additives in solid fuel [10], energetic compounds like plasticizers and binders with solid fuel [11] and manufacturing of grains with helical port shape [12]. However, all of these approaches suffer from some drawbacks.

The oxidizer injection characteristics have a significant part in improving the regression rate of the hybrid rocket because the whole process of combustion is severely affected by the pattern of the incoming oxidizer flow. In the hybrid rocket combustion process, oxidizer flows over the solid fuel grain leading to a boundary layer formation. The flame is formed inside the boundary layer. The heat from the flame travels toward the fuel surface, leading to pyrolysis. The heat flux of the pyrolyzed fuel acts as a hindrance and reduces the heat feedback to the fuel surface. Therefore, an injector is designed to create re-circulation zones inside the chamber such that convective heat transfer to the fuel surface is enhanced, thus increasing both regression rate and combustion efficiency [13]. There have been several researches over injection pattern and the three main types were axial, radial and swirl injectors. Pucci [14] studied the flame holding combustion instability for swirl injectors of $30^{\circ}$ and $60^{\circ}$ tangential angles and compared them with axial and radial injectors. The conducted experiments showed that a $60^{\circ}$ swirl injector produces more stable combustion than radial and $30^{\circ}$ swirl injectors as a result of the presence of a high central toroidal re-circulation zone in the combustion port, which in turn created preheating zones at the head end of the combustion chamber. In addition, a rise of $182 \%$ in the regression rate was recorded using a $60^{\circ}$ swirl injector as compared to an axial injector. Sliver losses with both axial and swirl injectors, on the other hand, were very high.

Carmicino and Sorge [15] conducted a series of tests to examine the regression rate performance of a hybrid rocket system study using conical axial and radial injectors. They concluded that axial injection of the oxidizer produced a higher regression rate and stable combustion as compared to radial injection, but the radial injector produced a uniform combustion along the fuel grain length and thus reduced sliver loss. Further, Martino et al. [16,17] proposed an optimized injector design which included both the axial and radial orifices to combine their characteristics. They observed a raise of $8 \%$ in the regression rate in comparison to the axial injector and smooth fuel consumption along the grain length. In this paper, an attempt was made to fabricate a multi-angle diverging injector to study the effects of the re-circulation zone over the regression rate and combustion efficiency of the hybrid rocket for both non-liquefying and liquefying fuels at various port diameters. Moreover, mass flux dependence on the fuel regression rate was observed.

\section{Experimental Setup}

The experimental set-up utilized in the present study is shown in Figure 1. It consists of a commercial oxygen cylinder having a maximum pressure of $2200 \mathrm{Psi}$, which was used to supply the oxygen utilizing the feed line made of brass and stainless steel $[18,19]$. It had various valves to control the output pressure and flow from feed line to the combustion chamber. For all the experiments, the pressure was regulated in the feed line to keep oxygen pressure at $300 \mathrm{Psi}$, in order to keep the oxidizer mass flow rate at $30 \mathrm{~g} / \mathrm{s}$ for all of the experiments. To calculate the oxidizer mass flow rate, the oxygen 
cylinder was placed on a weighing machine with a minimum count of $1 \mathrm{~g}$ and a reduction in cylinder weight was continuously recorded for the purpose.

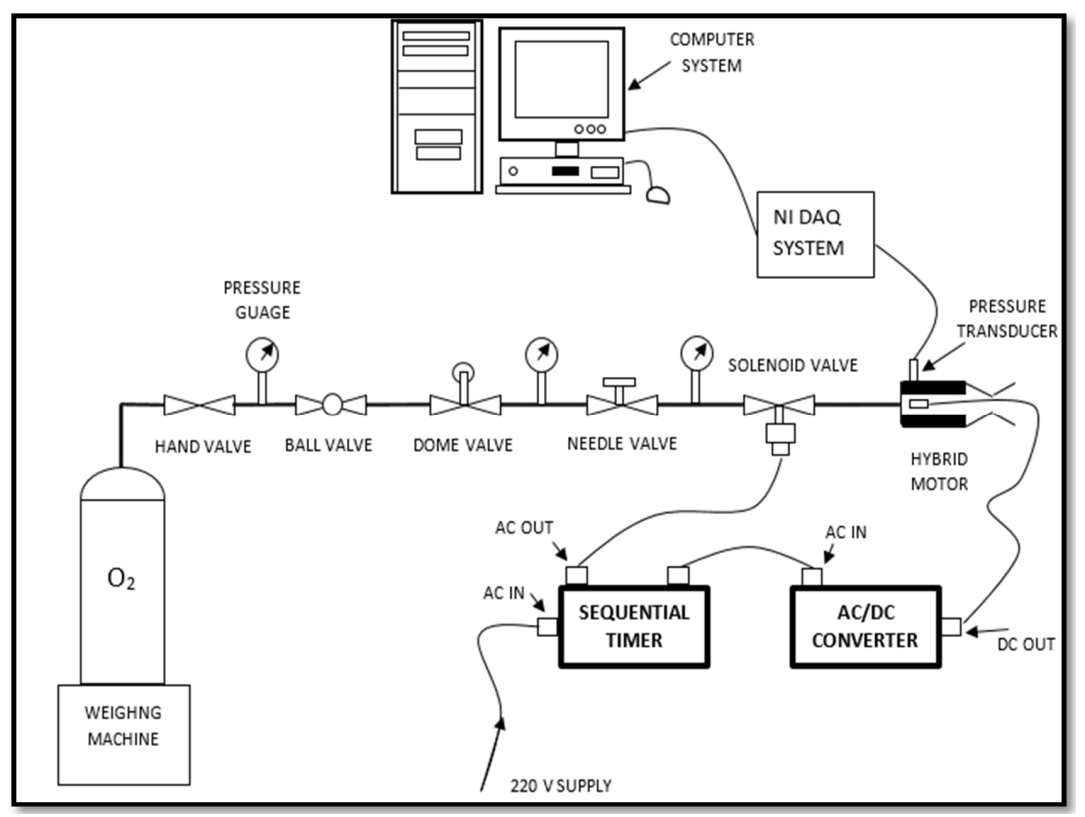

Figure 1. Complete layout of the experimental set-up.

A solenoid valve was provided at the end of the feed line or near the injection point of oxygen into the combustion chamber, to start and stop the supply of oxidizer into the chamber. For ignition, a bead of solid composite propellant was used. The composition of solid composite propellant bead was $70 \%$ ammonium perchlorate and 30\% PVC with plasticizer di-octyl phthalate (DOP). For igniting the propellant, the ignition system used was powered by a 12-Volt DC power supply through an AC/DC converter. The Selec 8-channel sequential timer was used to control the ignition system and solenoid valve.

The sequential timer was powered by $220 \mathrm{~V} \mathrm{AC}$ supply and, through outlet channels, it is connected to solenoid valves and an AC/DC converter, to provide AC supply. The sequential timer regulates the timings to power the solenoid valve and igniter i.e., solid propellant bead. At first, the sequential timer provides DC supply to the igniter through the AC/DC converter for about $3.70 \mathrm{~s}$ and ignites the solid propellant; after that it cuts off the supply to the igniter and switches on the supply to the solenoid valve. The solenoid valve is opened to allow oxidizer to flow into the combustion chamber for the desired time interval of operation. The combustion chamber pressure data was taken during firing using a pressure transducer. Data from the pressure transducer was received through a NI DAQ card and NI Signal Express software.

A lab scale hybrid motor was used for this study, as shown in Figure 2. The hybrid rocket motor was made of mild steel with a combustion chamber of length $188 \mathrm{~mm}$ and inner diameter of $50 \mathrm{~mm}$. The motor used an aluminium nozzle with graphite insert at the aft end. The hybrid motor at its aft end utilized a convergent-divergent nozzle of $10 \mathrm{~mm}$ throat diameter and area ratio of 6.25. The head end of the hybrid motor comprised of the injector plate from where the oxidizer was injected at the desired injection pressure. There was no pre or post chamber in the motor.

In this study, the two injectors used were shower head and multi-angle diverging injectors with an outer diameter of $110 \mathrm{~mm}$, the same as that of the combustion chamber, so that no air gap is left between the leading edges to avoid leakage of gaseous oxidizer. The 3-D CATIA model for the shower head and multi angle diverging injectors are shown in Figures 3 and 4a,b, respectively. Figure 3 shows the geometrical positions of 21 holes of $1 \mathrm{~mm}$ diameter, each in the shower head injector. One hole is 
drawn at the center and 8 and 12 holes are drilled at equal angular positions on two concentric circles of diameter $8 \mathrm{~mm}$ and $12 \mathrm{~mm}$, respectively.

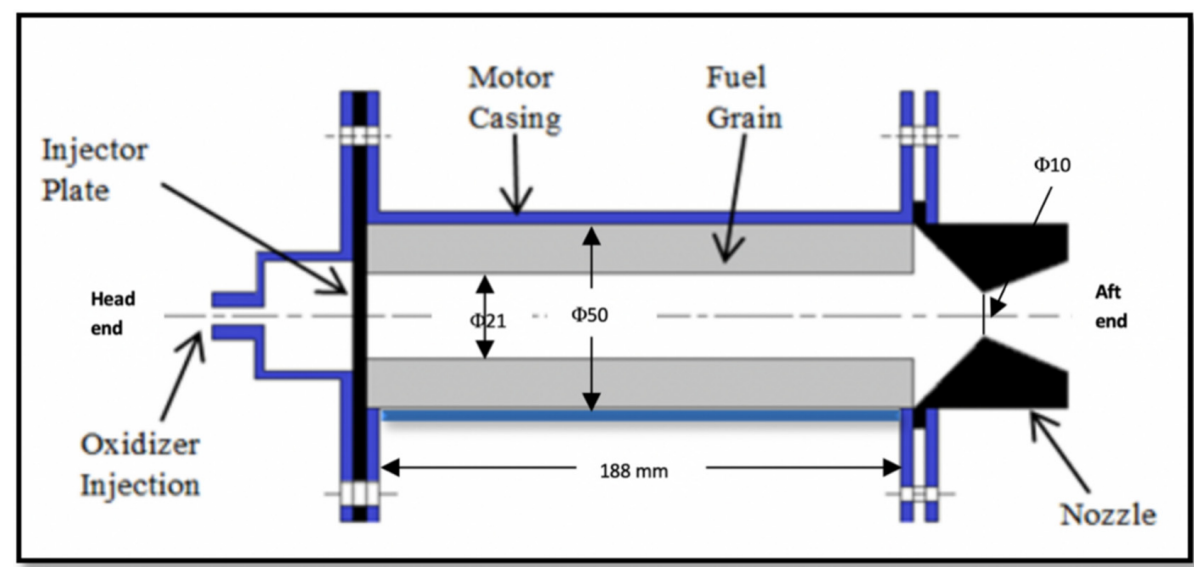

Figure 2. Schematic of lab-scale model of hybrid rocket motor.

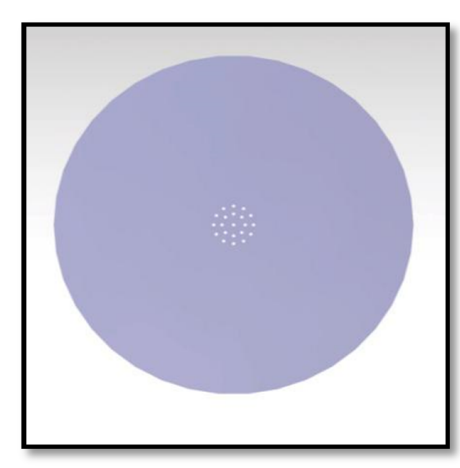

(a)

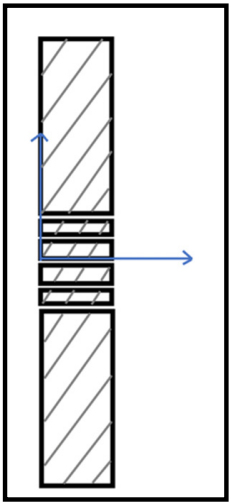

(b)

Figure 3. Catia V5 model of (a) shower head injector, (b) Exploded sectional view of shower head injector.

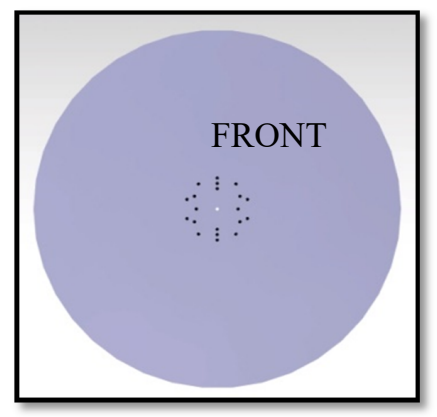

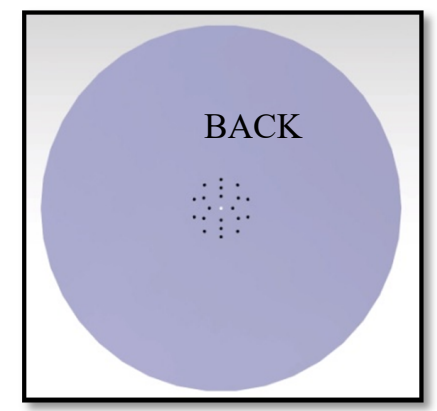

(a)

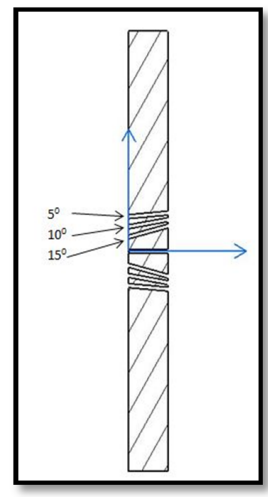

(b)

Figure 4. Catia V5 model of (a) Schematic diagram, (b) Sectional view of multi-angle diverging injector.

Figure $4 \mathrm{a}$ shows the front and back view of the novel (multi-angle diverging) injector with 21 holes of $1 \mathrm{~mm}$ diameter, with one hole at the center and 4,6 and 10 holes are drilled at three concentric circles of PCD of 7,12 and $16 \mathrm{~mm}$, respectively. The central hole is axial and the other holes drilled at three concentric circles of PCD of 7,12 and $16 \mathrm{~mm}$, making an angle of $15^{\circ}, 10^{\circ}$ and $5^{\circ}$ with the axis, respectively. For further incite, the sectional view of diverging angles was developed by CATIA V5, 
as shown in Figure $4 \mathrm{~b}$. The cross-sectional area of each hole and the number of holes in both injectors are the same, so that total discharge area of oxidizer to chamber should be the same for justifiable comparisons of performance of the injectors under study. The PCD of the outer concentric circles of both of the injectors is less than the port diameter of fuel grain.

The non-liquefying fuel utilized in the present work was polyvinyl chloride (PVC) with dehumidified plasticizer di-octyl phthalate (DOP) in a mixture ratio of $50: 50$ by weight. The homogenous slurry of powdered PVC and liquid DOP was casted in an aluminium mould of $200 \mathrm{~mm}$ length and $50 \mathrm{~mm}$ inner diameter with a mandrel of diameter $21 \mathrm{~mm}$, to prepare a tubular grain. The casted slurry was then kept inside the hot air oven for $4 \mathrm{~h}$ at $125^{\circ} \mathrm{C}$ for curing. The casted slurry is popularly known as fuel grain, with an outside diameter $50 \mathrm{~mm}$ and $188 \mathrm{~mm}$ length, whereas the inner hollow tubular portion is called port, with a diameter of $21 \mathrm{~mm}$ across its length, as shown in Figure 2. The liquefying fuel used in the present work was a combination of $30 \%$ microcrystalline wax and $70 \%$ paraffin wax. The melted wax was casted in the mould and cured at atmospheric conditions for $4 \mathrm{~h}$. The wax fuel was casted inside a PVC pipe for easy handling.

\section{Results and Discussion}

The section includes the regression rate and combustion efficiency studies using the multi-angle diverging injector and comparison with the conventional shower head injector. The fuel types utilized in the present study were PVC and paraffin wax fuels with gaseous oxygen as oxidizer.

\subsection{Effect of Injector Type}

In the present study, two injector types have been evaluated. One is the shower head injector i.e., axial type and other is the fabricated multi-angle diverging injector. Table A1 (Appendix A) summarizes the test conditions and regression rate obtained using both of the injector types, with PVC as fuel.

An increase of the average regression rate, using multi-angle diverging injector of around $8 \%$, was obtained as compared to the conventional shower head injector. The increase in average regression rate using the multi angle diverging injector is obtained because the oxidizer enters into the chamber through injector and impinges at three different locations on the fuel grain surface, creating more recirculation as compared to the shower head injector. This recirculation zone enhances the internal energy of the oxidizer flow, which is then converted into the kinetic energy of the oxidizer molecules, leading to a rise in heat flux at the head end. The average mass flux is enhanced due to a higher fuel mass flow rate at the head end before the formation of the boundary layer. This in turn diminishes the blocking effect due to fuel mass flux, as the core flow is strongly influenced by the directional flow structures that arise due to the unique injection method. Hence, a rise in the average regression rate was observed using multi-angle diverging injector. Figure 5 shows the average regression rate vs the average mass flux for both of the injector types. The power value of average mass flux of 0.35 is observed during experimentation utilizing multi-angle diverging injector, 0.68 using shower head injector. This clearly suggests that the injection pattern using multi-angle diverging injector affects the average regression rate due to jet impingement zone dynamics. The flow field in the port is dominated by the reattachment or impingement region, which results in an increase in the average regression rate, and a diminishing of the dependence of the average mass flux on the regression rate. Carmicino and Sorge [15] also reported similar dependence of mass flux with a power raised to 0.35 , which further supports the effect of impingement as obtained in the present case.

A 2-dimensional cold flow analysis of oxygen inside the combustion chamber was also carried out using Ansys fluent software in order to study the variation of oxidizer flow velocity (axial component) along the length of the combustion chamber, as shown in Figure $6 a, b$, using the two injector types. The combustion chamber is represented by uniform cross-sectional area, and, on the right end of the chamber, the converging-diverging area represents the nozzle. The analysis is based on the impact 
of axial components of oxidizer flow velocity along the length of chamber, to show the disturbance created by the radial entrance of the oxidizer inside the chamber using the novel injector.

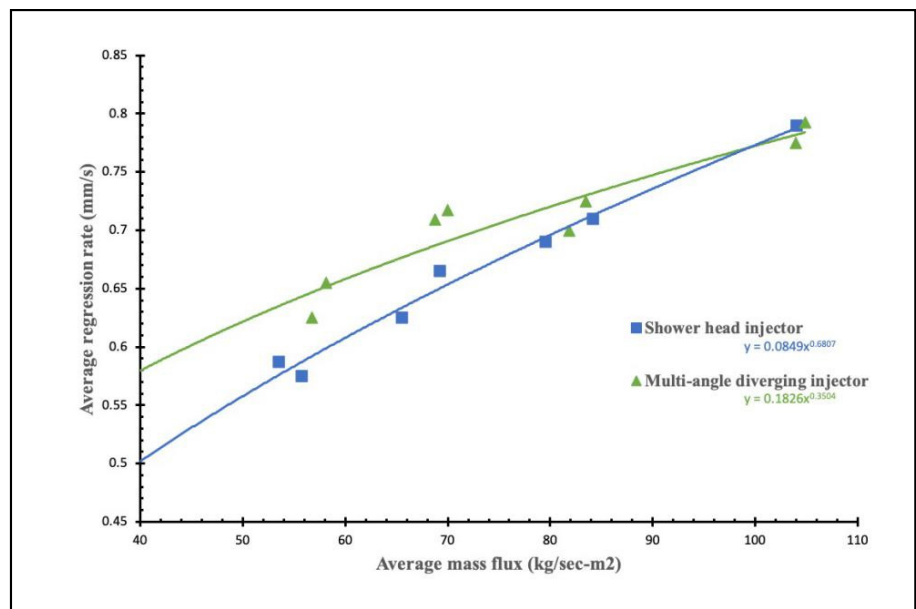

Figure 5. Average regression rate vs. average mass flux using the two injector designs for PVC fuel.

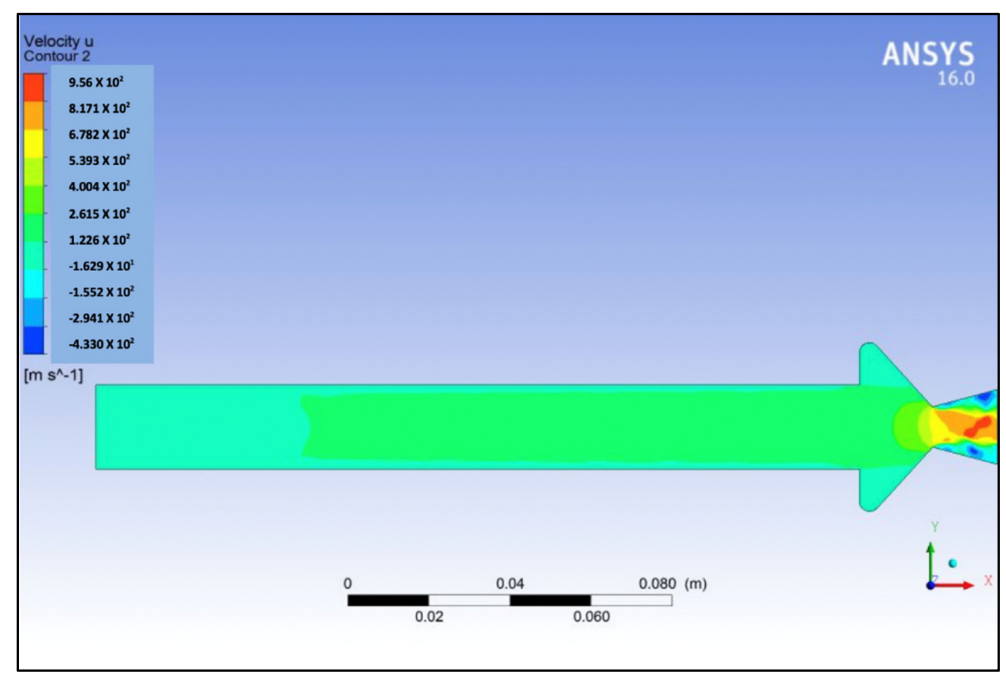

(a)

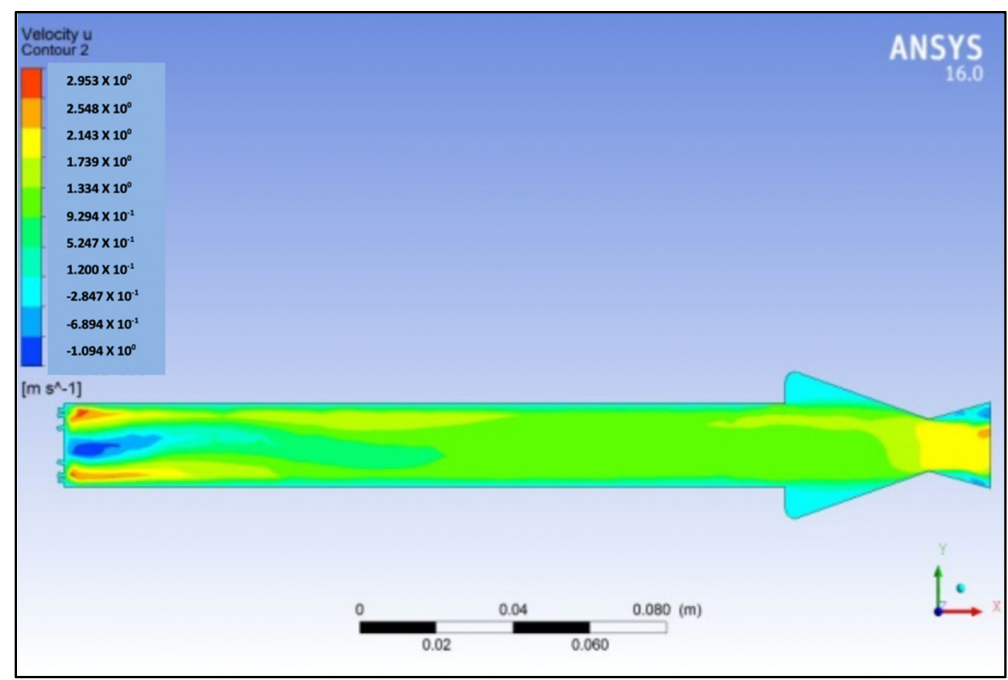

(b)

Figure 6. Axial velocity contour using (a) shower head injector and (b) multi-angle diverging injector. 
The velocity inside the nozzle is beyond the scope of discussion as it does not affect the combustion process inside the chamber. Figure 6a depicts that, for the shower head injector, the axial velocity component gradually increases from $122 \mathrm{~m} / \mathrm{s}$ to $400 \mathrm{~m} / \mathrm{s}$ along the length of the combustion chamber. In the case of the multi-angle diverging injector, Figure $6 \mathrm{~b}$, the axial velocity of the oxidizer is quite low, of the order of around $2.9 \mathrm{~m} / \mathrm{s}$, and is even negative. These values suggest the formation of a recirculation zone near the head end of the chamber due to radial entry of the oxidizer, considerably reduces the axial component of velocity. Contrary to this, the recirculation of the oxidizer flow at the head end increases the residence time of the gases inside the chamber. Thus, cold flow analysis suggested more turbulence in oxidizer flow near the head end of the port using multi-angle diverging injector, which led to an increase in the residence time for an actual combustion process in a real scenario. On the other hand, a linear increase in velocity was observed using the shower head injector with higher values approaching downstream of the combustion chamber, which results in shorter residence time and hence incomplete combustion occurs.

A study of the local regression rate along the chamber length of $188 \mathrm{~mm}$ was also carried out and Figure 7 shows the trend of local regression rate versus the ratio of axial length to grain length $(x / L)$ of the grain using the two injector designs. The web thickness uniformity was obtained downstream of the flow in the case of the multi-angle diverging injector, as shown in Figure 7. The graph shows that the regression rate at the head end is higher in the case of the multi-angle diverging injector by $83.1 \%$, as compared to the shower head injector. In the case of the multi-angle diverging injector, the combustion starts at the head end itself as the heat flux is high due to increased residence time of the oxidizer and, as the flow goes downstream, the particles flow uniformly and reduce sliver loss. This uniformity occurs presumably due to the stagnation point heat transfer near the edge of the impinging oxidizer jet. Analogous observations were reported by Caravella et al. [20].

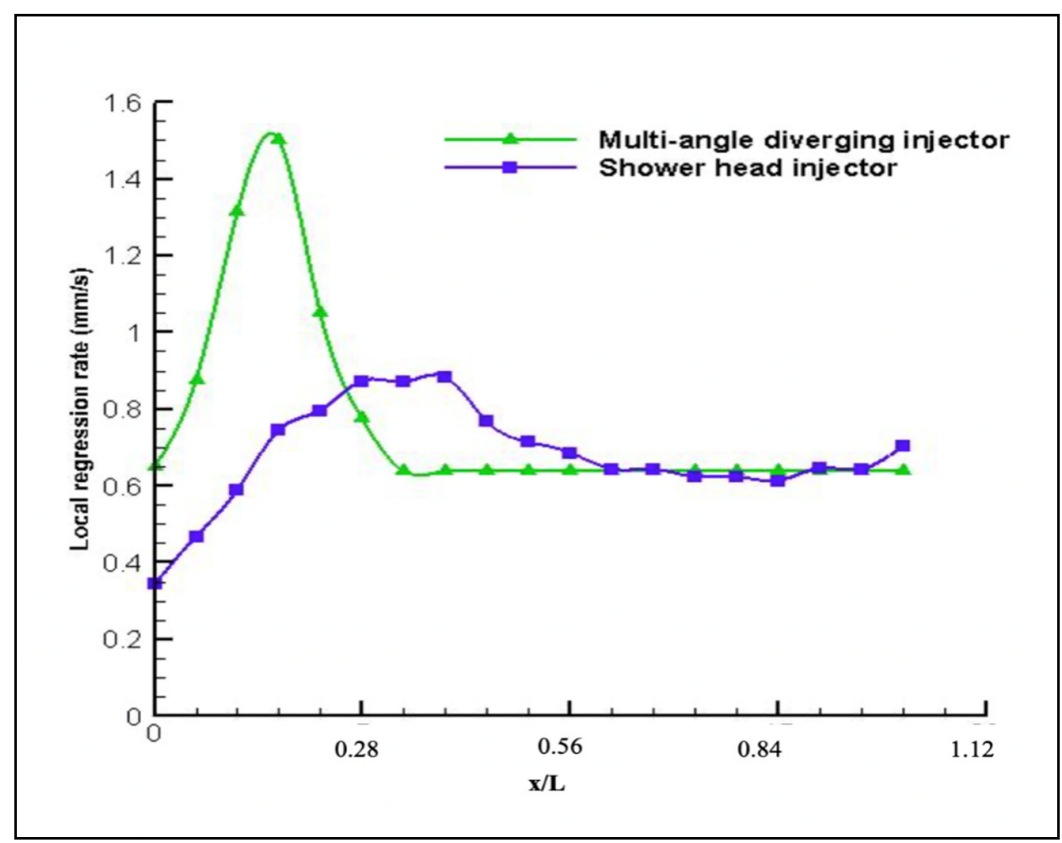

Figure 7. Local regression rate vs. $\mathrm{x} / \mathrm{L}$ using the two injector designs using PVC fuel.

The photographic view of burnt PVC grain used in the shower head injector and multi angle diverging injector are shown in Figure 8a,b, respectively. The depressions at the head end of the fuel grain using the multi-angle diverging injector clearly indicate that, due to the larger residence time for oxidizer in the beginning, using multi angle diverging injector helps to burn the larger portion of grain, initially in comparison to fuel grain burnt using the shower head injector. 


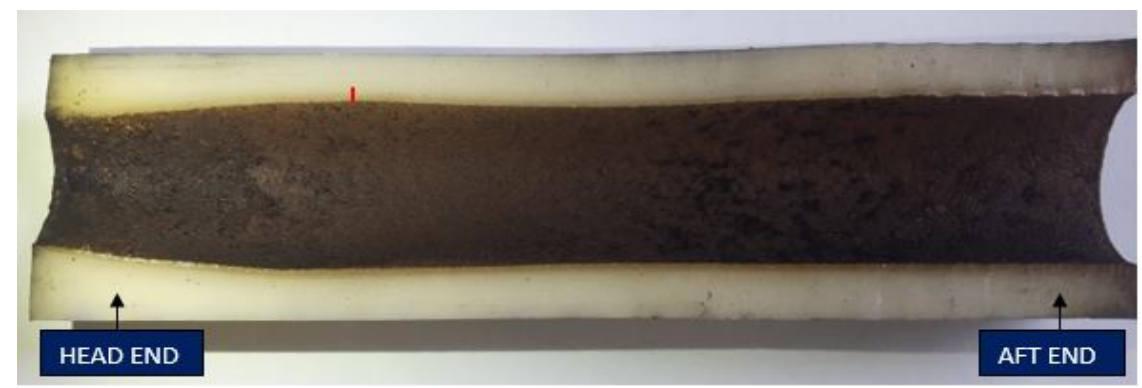

(a)

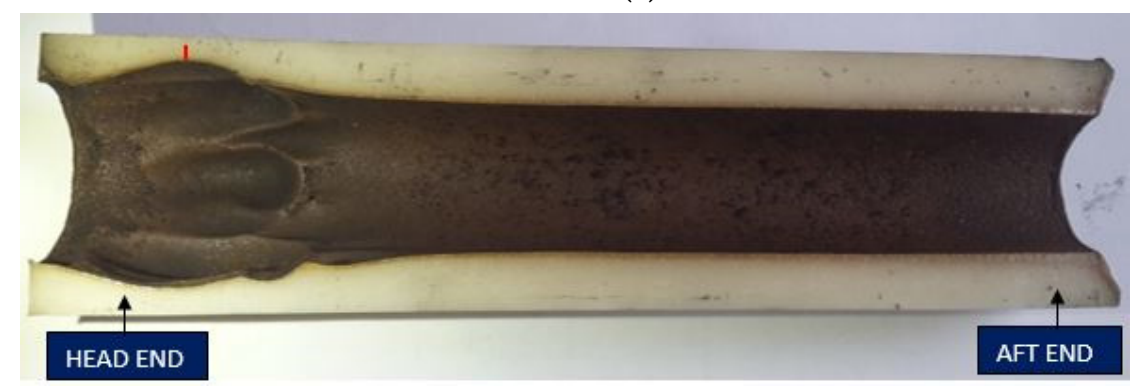

(b)

Figure 8. Burnt PVC grain using (a) shower head injector and (b) multi-angle diverging injector.

\subsection{Effect of Port Diameter}

In the present study, three port diameters of 21,24 and $28 \mathrm{~mm}$ were taken to study the effect of the port diameter on the regression rate using multi-angle diverging injector for PVC fuel grain. Table 1 shows the average regression rate studies for the varying port diameter.

Table 1. Average regression rate for the varying port diameter using multi-angle diverging injector.

\begin{tabular}{ccc}
\hline Port Diameter (mm) & Average Regression Rate (mm/s) & Burn Time (s) \\
\hline 21 & 0.74 & 6 \\
\hline 24 & 0.73 & 6 \\
\hline 28 & 0.67 & 6 \\
\hline
\end{tabular}

Figure 9 shows the variation of local regression rate for various port diameters versus the ratio of axial length to grain length $(\mathrm{x} / \mathrm{L})$. The figure depicts that near the head end, up to $5 \mathrm{~cm}$ distance, the local regression rate increases sharply and then decreases; this behavior was observed for all three of the port diameters. However, the maximum rise in local regression rate was observed with a port diameter of $21 \mathrm{~mm}$. Further, across the length of the chamber until the aft end, the curves for all port diameter become flat and comparatively a higher local regression rate was observed for $24 \mathrm{~mm}$ port diameter. However, after $5 \mathrm{~cm}$ distance from the head end, the decrease in average regression rate is because the average mass flux reduces due to a higher increase in the port area. This could be explained by the local regression rate along the grain length depicting a decrease in the heat flux at the head end, which is observed with the increase in the port diameter as the oxidizer mass flux reduces, and the same can be observed in Figure 9. Carmicino et al. [21] also reported a decrease in regression rate with increasing port diameter for a converging nozzle. 


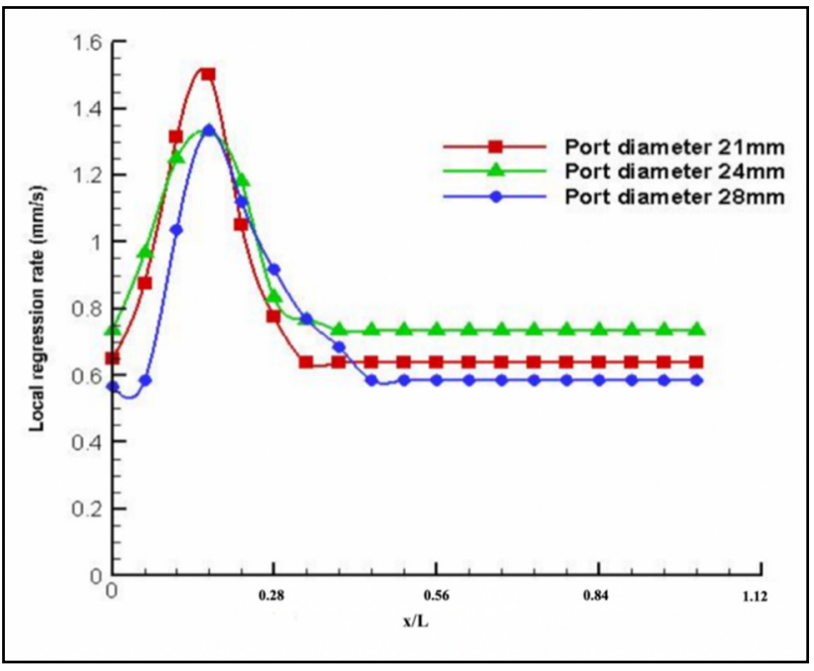

Figure 9. Local regression rate vs. $\mathrm{x} / \mathrm{L}$ using multi-angle diverging injector by varying port diameter.

\subsection{Effect of Fuel Type}

The liquefying fuel utilized in the present study is paraffin wax with gaseous oxygen as oxidizer. As stated in the literature, paraffin wax burns 2-3 times faster than the polymeric-based fuels [22,23]. Interrupted test firing of $1 \mathrm{~s}$ each for three times was conducted to calculate the regression rate using the weight loss method. Table A2 summarizes the test conditions and regression rate obtained using both of the injector types with paraffin wax as fuel. The results suggested an increase in the average regression rate using a multi-angle diverging injector as compared to a shower head injector by $36.14 \%$.

The graphical representation of the values of regression rate with respect to average mass flux of Table A2 is shown in Figure 10. Figure 10 depicts that the average regression rate increases with an increase in the average mass flux for both of the injector designs. However, the rise in average regression rate with the increase of average mass flux is steeper for the multi-angle diverging injector in comparison to the shower head injector; it is due to the combined effect of injector design as well as the effect of melt-layer formation by paraffin wax fuel. The multi-angle diverging injector creates higher recirculation at the head end as compared to the shower head and, therefore, the mixing of oxidizer with fuel droplets is enhanced. This results in an increase of the average regression rate.

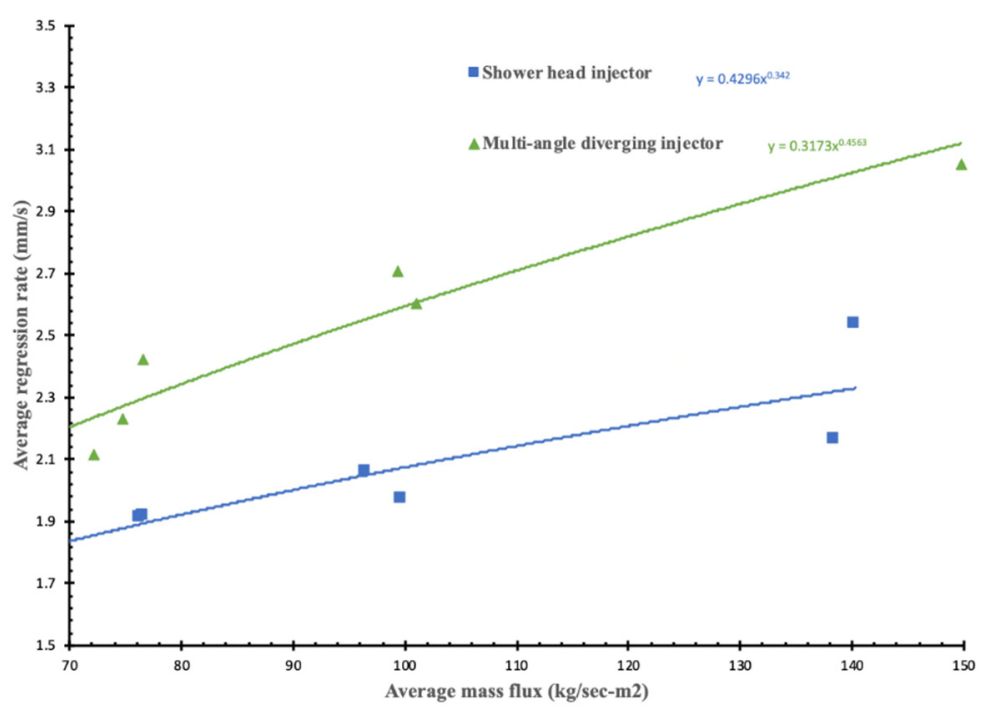

Figure 10. Average regression rate vs. average mass flux using the two different injector designs for paraffin wax fuel. 


\subsection{Effect on Combustion Efficiency}

In the present study, combustion efficiency performance was also compared for the two injector designs with both liquefying and non-liquefying fuel types. The ${ }^{*}$ efficiency was calculated using the following formulas:

$$
\begin{gathered}
C_{\text {exp }}^{*}=\frac{P_{c} A_{t}}{\dot{m}_{o x}+\dot{m}_{f}} \\
\eta_{c}=\frac{C_{\text {exp }}^{*}}{C_{\text {theo }}^{*}}
\end{gathered}
$$

The average chamber pressure was measured using the pressure transducer at the aft end of the chamber with obtained pressure curves shown in Figures 11 and 12, and theoretical characteristic velocity was obtained using NASA CEA software.

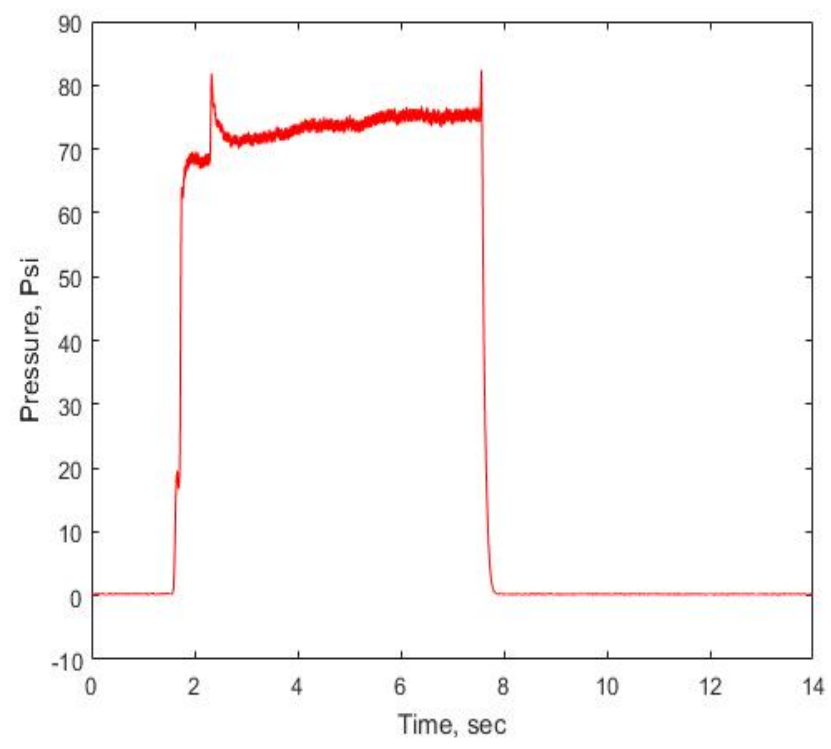

(a)

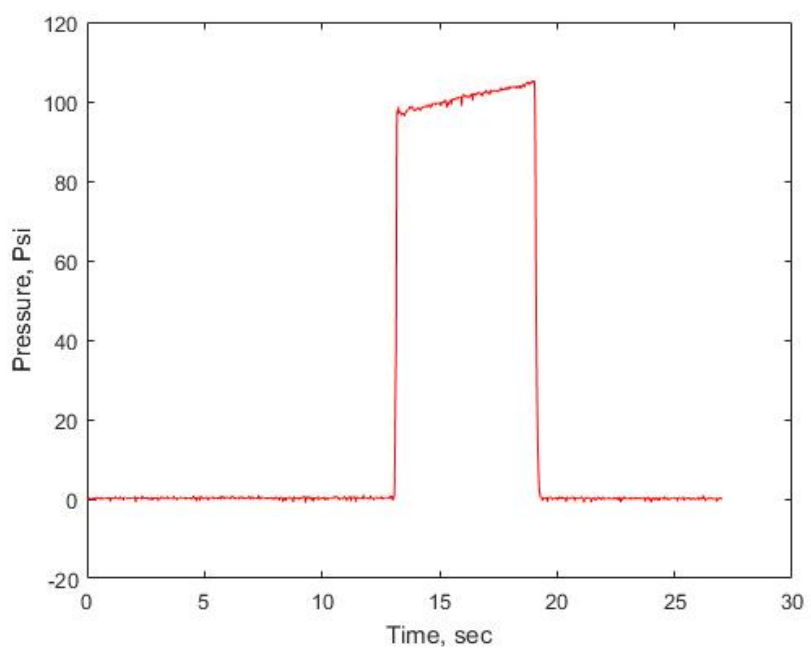

(b)

Figure 11. Pressure-time data using (a) shower head injector and (b) multi-angle diverging injector for PVC fuel. 


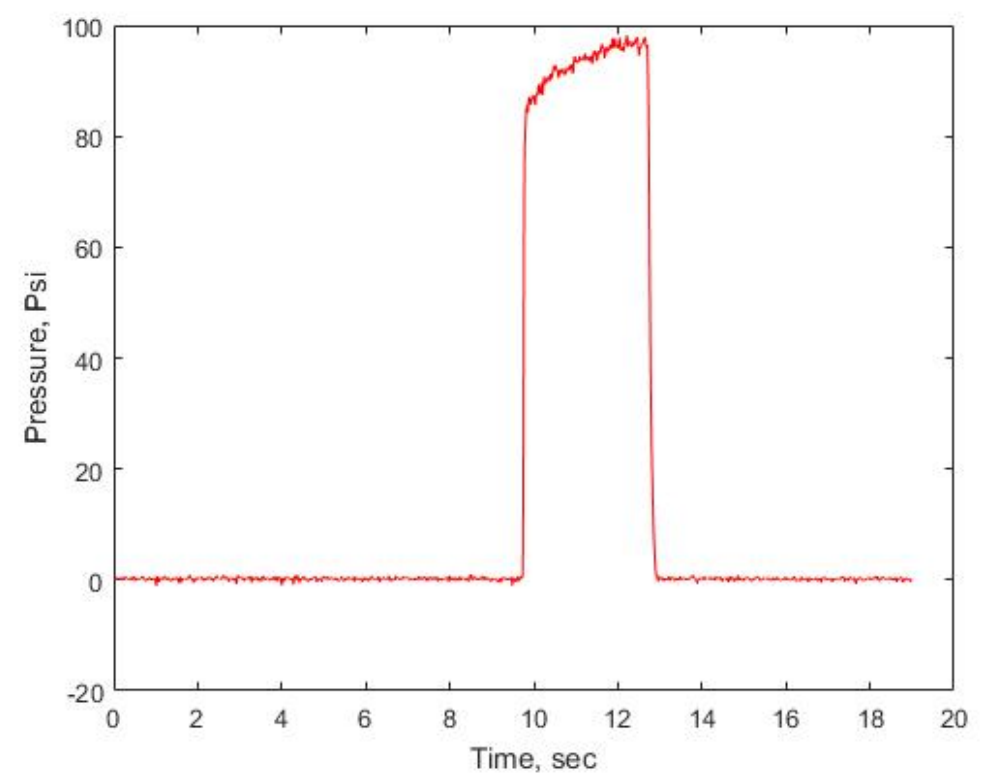

(a)

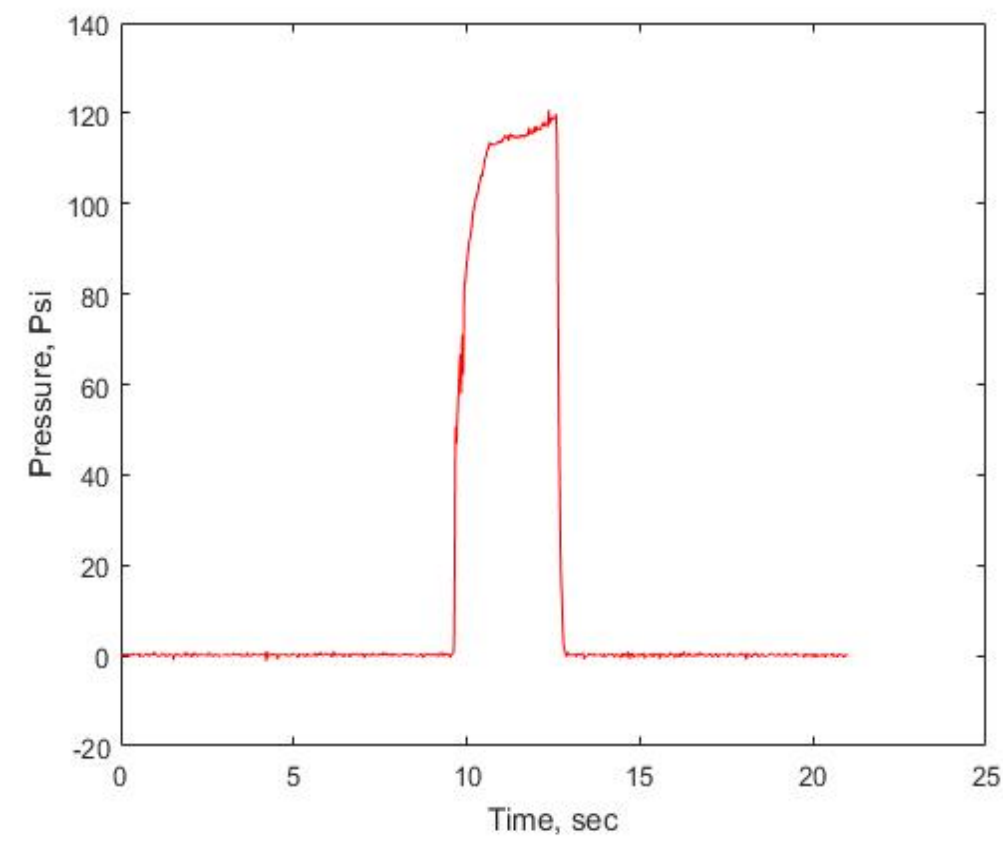

(b)

Figure 12. Pressure-time data using (a) shower head injector and (b) multi-angle diverging injector for paraffin wax.

Table 2 summarizes the combustion efficiency results. The multi-angle diverging injector induces higher mixing of oxidizer and pyrolyzed fuel and hence a rise in combustion efficiency was observed in comparison to the shower head injector. In comparison to PVC fuel, combustion efficiency has decreased in the case of paraffin wax using shower head and multi-angle diverging injectors, by around $3 \%$ and $24.4 \%$, respectively. This decrement has been observed due to dual phase flow dynamics during the combustion of paraffin wax, as liquid droplets of wax and gaseous oxidizer mix and undergo chemical reaction. In comparison to wax, polymeric fuel i.e., PVC undergoes a single-phase flow as both oxidizer and pyrolyzed fuel are in the gaseous phase. 
Table 2. Combustion efficiency data for two injector designs.

\begin{tabular}{cccccc}
\hline Injector Type & Fuel Type & $\begin{array}{c}\text { Average } \\
\text { Chamber } \\
\text { Pressure (Psi) }\end{array}$ & O/F Ratio & $\begin{array}{c}\text { Theoretical } \\
\text { Characteristic } \\
\text { Velocity (m/s) }\end{array}$ & $\begin{array}{c}\text { Combustion } \\
\text { Efficiency } \\
\text { (\%) }\end{array}$ \\
\hline $\begin{array}{c}\text { Shower head } \\
\text { injector }\end{array}$ & PVC & 74.26 & 2.55 & 1558.5 & 61.9 \\
\hline $\begin{array}{c}\text { Multi-angle } \\
\text { diverging } \\
\text { injector }\end{array}$ & PVC & 101.33 & 0.76 & 1505.5 & 85.7 \\
\hline $\begin{array}{c}\text { Shower head } \\
\text { injector }\end{array}$ & Paraffin wax & 93.83 & 0.96 & 1382.3 & 60.23 \\
\hline $\begin{array}{c}\text { Multi-angle } \\
\text { diverging } \\
\text { injector }\end{array}$ & Paraffin wax & 115.79 & 0.73 & 1298.3 & 68.90 \\
\hline
\end{tabular}

\section{Conclusions}

In the present study, the effects of changing oxidizer patterns were studied on the liquefying and non-liquefying fuels by designing a new injector type i.e., the multi-angle diverging injector. The following were the conclusions drawn from the experiments conducted:

1. The multi-angle diverging injector showed a better performance by increasing the average regression rate and combustion efficiency by around $8 \%$ and $38.45 \%$, respectively, for non-liquefying fuel, i.e., PVC+DOP, in comparison to the shower head injector.

2. The multi-angle diverging injector showed the better performance by increasing the average regression rate and combustion efficiency by around $36.14 \%$ and $14.4 \%$, respectively, for liquefying fuel, i.e., paraffin wax, in comparison to the shower head injector.

3. Uniform burning downstream of the combustion chamber and sliver loss reduction was observed using the multi-angle diverging injector for PVC+DOP fuel, in comparison to non-uniform burning observed using the shower head injector.

4. The power exponent value of around 0.35 was obtained for multi-angle diverging injectors and 0.68 for the shower head injector, depicting the effect of jet zone dynamics on the regression rate for the PVC+DOP fuel type.

Author Contributions: P.B.: Research and conceptualisation, Experimental work, writing manuscript. S.B.: Supervisor. All authors have read and agreed to the published version of the manuscript.

Funding: No external funding was received. The APC was funded by the corresponding author (PRAGYA BERWAL) herself.

Conflicts of Interest: The authors declare no conflict of interest.

\section{Nomenclature}

\begin{tabular}{|c|c|c|c|}
\hline$A_{t}$ & Throat area, $\mathrm{m}^{2}$ & $\operatorname{Re}$ & Reynolds number \\
\hline$A_{P}$ & Port area, $\mathrm{m}^{2}$ & $\mathrm{~B}$ & Blowing number \\
\hline a & Oxidizer mass flux constant & $\mathrm{m}_{\mathrm{f}}$ & mass of the fuel consumed, $\mathrm{g}$ \\
\hline $\mathrm{n}$ & Power exponent of mass flux & di & initial port diameter, $\mathrm{mm}$ \\
\hline$\rho_{\mathrm{f}}$ & Density of fuel, $\mathrm{kg} / \mathrm{m}^{3}$ & $\mathrm{~L}_{\mathrm{g}}$ & length of the fuel grain, $\mathrm{mm}$ \\
\hline$C^{*} \exp$ & Experimental characteristic velocity, $\mathrm{m} / \mathrm{s}$ & $t_{b}$ & burn time, s \\
\hline$C^{*}$ theo & Theoretical characteristic velocity, m/s & $\dot{\mathrm{r}}$ & regression rate, $\mathrm{mm} / \mathrm{s}$ \\
\hline $\mathrm{C}^{*}$ ox & Characteristic velocity of oxidizer, $\mathrm{m} / \mathrm{s}$ & $\dot{\mathrm{m}}_{\mathrm{ox}}$ & Oxidizer mass flow rate, $\mathrm{g} / \mathrm{s}$ \\
\hline $\mathrm{L} / \mathrm{D}$ & Ratio of total length to initial port diameter of fuel & $\dot{\mathrm{m}}_{\mathrm{f}}$ & Fuel mass flow rate, $\mathrm{g} / \mathrm{s}$ \\
\hline $\mathrm{I}_{\mathrm{sp}}$ & Specific impulse, Ns/kg & $\eta$ & Combustion efficiency \\
\hline $\mathrm{P}_{\mathrm{C}}$ & Average chamber pressure, Psi & $\dot{\mathrm{m}}_{\mathrm{t}}$ & Total mass flow rate of propellant, $\mathrm{g} / \mathrm{s}$ \\
\hline $\bar{G}$ & Average mass flux, $\mathrm{kg} / \mathrm{s} . \mathrm{m}^{2}$ & $\mathrm{~T}_{\mathrm{c}}$ & Combustion chamber temperature, $\mathrm{K}$ \\
\hline $\mathrm{G}_{\mathrm{ox}}$ & Oxidizer mass flux, kg/s. $\mathrm{m}^{2}$ & $\mathrm{~T}_{\mathrm{ox}}$ & Oxidizer temperature, $\mathrm{K}$ \\
\hline
\end{tabular}




\section{Appendix A}

Table A1. Interrupted test firings for PVC fuel.

\begin{tabular}{|c|c|c|c|c|}
\hline Injector Type & $\begin{array}{l}\text { Regression Rate } \\
\quad(\mathrm{mm} / \mathrm{s})\end{array}$ & $\begin{array}{l}\text { Oxidizer Mass } \\
\text { Flux }\left(\mathrm{kg} / \mathrm{s} . \mathrm{m}^{2}\right)\end{array}$ & $\begin{array}{l}\text { Average Mass } \\
\text { Flux }\left(\mathrm{kg} / \mathrm{s} . \mathrm{m}^{2}\right)\end{array}$ & $\begin{array}{l}\text { Burn } \\
\text { Time (s) }\end{array}$ \\
\hline $\begin{array}{c}\text { Shower head } \\
\text { injector (axial } \\
\text { injection) }\end{array}$ & $\begin{array}{ll}\text { 1. } & 0.698 \\
\text { 2. } & 0.710 \\
\text { 3. } & 0.665 \\
\text { 4. } & 0.562\end{array}$ & $\begin{array}{l}76.19 \\
60.13 \\
48.88 \\
41.31\end{array}$ & $\begin{array}{l}102.86 \\
84.18 \\
69.25 \\
57.15\end{array}$ & $\begin{array}{l}2 \\
2 \\
2 \\
2\end{array}$ \\
\hline $\begin{array}{c}\text { Multi-angle } \\
\text { diverging injector }\end{array}$ & $\begin{array}{ll}\text { 1. } & 0.793 \\
\text { 2. } & 0.700 \\
\text { 3. } & 0.709 \\
\text { 4. } & 0.625\end{array}$ & $\begin{array}{l}74.92 \\
58.44 \\
47.41 \\
39.62\end{array}$ & $\begin{array}{l}104.88 \\
81.82 \\
68.75 \\
56.78\end{array}$ & $\begin{array}{l}2 \\
2 \\
2 \\
2\end{array}$ \\
\hline
\end{tabular}

Table A2. Interrupted test firings for Paraffin wax fuel.

\begin{tabular}{|c|c|c|c|c|}
\hline Injector Type & $\begin{array}{c}\text { Regression Rate } \\
(\mathrm{mm} / \mathrm{s})\end{array}$ & $\begin{array}{l}\text { Oxidizer Mass } \\
\text { Flux }\left(\mathrm{kg} / \mathrm{s} . \mathrm{m}^{2}\right)\end{array}$ & $\begin{array}{l}\text { Average Mass } \\
\text { Flux }\left(\mathrm{kg} / \mathrm{s} . \mathrm{m}^{2}\right)\end{array}$ & $\begin{array}{c}\text { Burn } \\
\text { Time (s) }\end{array}$ \\
\hline $\begin{array}{l}\text { Shower head } \\
\text { injector (axial } \\
\text { injection) }\end{array}$ & $\begin{array}{ll}\text { 1. } & 2.17 \\
\text { 2. } & 1.98 \\
\text { 3. } & 1.91\end{array}$ & $\begin{array}{l}71.22 \\
51.26 \\
39.27\end{array}$ & $\begin{array}{c}138.39 \\
99.61 \\
76.32\end{array}$ & $\begin{array}{l}1 \\
1 \\
1\end{array}$ \\
\hline $\begin{array}{c}\text { Multi-angle } \\
\text { diverging injector }\end{array}$ & $\begin{array}{ll}\text { 1. } & 3.12 \\
\text { 2. } & 2.71 \\
\text { 3. } & 2.42\end{array}$ & $\begin{array}{l}65.68 \\
42.61 \\
31.05\end{array}$ & $\begin{array}{l}151.08 \\
99.42 \\
76.61\end{array}$ & $\begin{array}{l}1 \\
1 \\
1\end{array}$ \\
\hline
\end{tabular}

\section{References}

1. Altman, D.; Humble, R. Hybrid rocket propulsion systems. In Space Propulsion Analysis and Design, 1st ed.; Humble, R.W., Henry, G.N., Larson, W.J., Eds.; McGraw-Hill: New York, NY, USA, 1995; pp. 365-401.

2. Sutton, G.P.; Biblarz, O. Hybrid Propellant Rockets. In Rocket Propulsion Elements, 7th ed.; John Wiley \& Sons: New York, NY, USA, 2001; pp. 585-593.

3. Marxman, G.A.; Gilbert, M. Turbulent Boundary Layer Combustion in the Hybrid Rocket. Symp. (Int.) Combust. 1963, 9, 371-383. [CrossRef]

4. Smoot, L.D.; Price, C.F. Pressure Dependence of Hybrid Fuel Regression Rates. AIAA J. 1967, 5, $102-106$. [CrossRef]

5. Wooldridge, C.E.; Marxman, G.A.; Kier, R.J. Investigation of Combustion Instability in Hybrid Rockets; Stanford Research Institute: Stanford, CA, USA, 1969.

6. Sankaran, V. Computational Fluid Dynamics Modelling of Hybrid rocket Flow-fields. In Fundamentals of Hybrid Rocket Combustion and Propulsion; Kuo, K., Chiaverini, M., Eds.; Progress in Astronautics and Aeronautics, AIAA: Reston, VA, USA, 2007; Volume 218, pp. 323-349.

7. Kumar, R.; Ramakrishna, P.A. Effect of Protrusion on the Enhancement of Regression Rate. Aerosp. Sci. Technol. 2014, 39, 169-178. [CrossRef]

8. Kim, S.; Lee, J.; Kim, G.; Cho, J.; Kim, J.; Moon, H.; Sung, H.; Park, S. Combustion Characteristics of the Cylindrical Multiport Grain for Hybrid Rocket Moto. In Proceedings of the 45th AIAA/ASME/SAE/ASEE Joint Propulsion Conference \& Exhibit, Denver, CO, USA, 2-5 August 2009.

9. Carrick, P.G.; Larson, C.W. Lab Scale Test and Evaluation of Cryogenic Solid Hybrid Rocket Fuels. In Proceedings of the 31st AIAA/ASME/SAE/ASEE Joint Propulsion Conference and Exhibit, San Diego, CA, USA, 10-12 July 1995. 
10. Thomas, J.C.; Petersen, E.L.; DeSain, J.D.; Ridlehuber, M.N.; Brady, B.B. Hybrid Rocket Burning Rate Enhancement by Nano-scale Additives in HTPB Fuel Grains. In Proceedings of the 50th AIAA/ASME/SAE/ASEE Joint Propulsion Conference, Cleveland, OH, USA, 28-30 July 2014.

11. Dario, P. Approaches to Low Fuel Regression Rate in Hybrid Rocket Engines. Int. J. Aerosp. Eng. $2012,2012$. [CrossRef]

12. Lee, C.; Na, Y.; Byun, J.W.L.Y.H. Effect of Induced Swirl Flow on Regression rate of Hybrid Rocket Fuel by Helical Grain Configuration. Aerosp. Sci. Technol. 2007, 11, 68-76. [CrossRef]

13. Carmicino, C.; Sorge, A.R. Role of Injection in Hybrid Rockets Regression Rate Behaviour. J. Propuls. Power 2005, 21, 606-612. [CrossRef]

14. Pucci, J.M. The Effects of Swirl Injector Design on Hybrid Flame-Holding Combustion Instability. In Proceedings of the 38th AIAA/ASME/SAE/ASEE Joint Propulsion Conference and Exhibit, Indianapolis, Indiana, 7-10 July 2002; pp. 2002-3578.

15. Carmicino, C.; Sorge, A.R. Performance comparison between two different injector configurations in a hybrid rocket. Aerosp. Sci. Technol. 2007, 11, 61-67. [CrossRef]

16. Di Martino, G.D.; Malgieri, P.; Carmicino, C.; Savino, R. A Simplified Computational Fluid-Dynamic Approach to the Oxidizer Injector Design in Hybrid Rockets. Acta Astronaut. 2016, 129, 8-21. [CrossRef]

17. Di Martino, G.D.; Carmicino, C.; Savino, R. Transient Computational Thermofluid-Dynamic Simulation of Hybrid Rocket Internal Ballistics. J. Propuls. Power 2017, 33, 1395-1409. [CrossRef]

18. Berwal, P.; Biswas, S. Investigating the Effect of Injector Type on the Regression Rate of the Hybrid Rocket. In Proceedings of the 11th International High Energy Materials Conference \& Exhibits, Pune, India, 23-25 November 2017.

19. Berwal, P.; Biswas, S. Study the Effect of Axi-swirl Injector on the Regression Rate of the Hybrid Rocket. In Proceedings of the 33rd National Convention of Aerospace Engineers at Iei, Pune India, 16-17 November 2019.

20. Caravella, J.R.; Heister, S.D.; Wernimont, E.J. Characterization of Fuel Regression in a Radial Flow Hybrid Rocket. J. Propuls. Power 1998, 14, 51-56. [CrossRef]

21. Bianchi, D.; Nasuti, F.; Carmicino, C. Hybrid Rockets with axial injector: Port Diameter effect on fuel regression rate. J. Propuls. Power 2016, 32, 984-996. [CrossRef]

22. Karabeyoglu, M.A.; Cantwell, B.J.; Altman, D. Development and testing of paraffin-based hybrid rocket fuels. In Proceedings of the 37th AIAA/ASME/SAE/ASEE Joint Propulsion Conference and Exhibit, Salt Lake City, UT, USA, 8-11 July 2001; pp. 2001-4503.

23. Karabeyoglu, M.A.; Altman, D.; Cantwell, B.J. Combustion of liquefying hybrid propellants: Part 1, General theory. J. Propuls. Power 2002, 18, 610-620. [CrossRef] 